\title{
THE EFFECT OF EDUCATION AND R\&D ON TOURISM SPENDING IN OECD GOUNTRIES: AN EMPIRICAL STUDY
}

\author{
Beata Gavurova $^{1 *}$, Jaroslav Belas ${ }^{2}$, Katarina Zvarikova ${ }^{3}$, Martin Rigelsky ${ }^{4}$ \\ and Viera Ivankova ${ }^{5}$ \\ ${ }^{12)}$ Tomas Bata University in Zlín, Zlín, Czech Republic \\ ${ }^{3)}$ University of Zilina, Zilina, Slovak Republic \\ ${ }^{4) 5)}$ University of Prešov in Prešov, Prešov, Slovak Republic
}

\section{Please cite this article as:}

Gavurova, B., Belas, J., Zvarikova, K., Rigelsky, M. and Ivankova, V., 2021. The Effect of Education and R\&D on Tourism Spending in OECD Countries: An Empirical Study. Amfiteatru Economic, 23(58), pp. 806-823.

\section{DOI: $10.24818 / \mathrm{EA} / 2021 / 58 / 806$}

\section{Article History}

Received: 10 March 2021

Revised: 8 May 2021

Accepted: 22 June 2021

\begin{abstract}
The aim of the presented study was to evaluate the effects of education and research and development $(R \& D)$ on tourism spending in a sample of OECD countries. The analyses were performed on the basis of data on tourism spending and data on education and R\&D. The research included 36 OECD countries, which were analysed for the period 2010-2019. Robust estimation was used in the panel data models. The results revealed the effect of $\mathrm{R} \& \mathrm{D}$ on leisure tourism spending $(\mathrm{R} \& \mathrm{D} \rightarrow \mathrm{LTS})$ and the effect of $\mathrm{R} \& \mathrm{D}$ on visitor exports (foreign spending) (R\&D $\rightarrow$ VEFS) with positive coefficients. On this basis, it can be concluded that improvements in R\&D can lead to increased leisure tourism spending as well as foreign spending. The countries such as Latvia, Chile, the Slovak Republic, Mexico, Lithuania, Turkey, Poland, Greece, Estonia, and Hungary have a great potential for an improvement in $\mathrm{R} \& \mathrm{D}$, which may also result in a growth of tourism spending. The research was focused on the macroeconomic perspective of education and R\&D and their effect on tourism spending as key economic indicators. The study provides interesting findings that are useful for policy makers in revitalizing the tourism sector through the effective implementation of policies and strategies aimed at increasing tourism spending. The study also enriches and contributes to the knowledge about the relationships between economic development and the development of the tourism sector.
\end{abstract}

Keywords: tourism, innovation, spending, education, tertiary education, research and development (R\&D).

JEL Classification: C38, L83, F43, R11

\footnotetext{
* Corresponding author, Beata Gavurova-e-mail: gavurova@utb.cz

Authors' ORCID:

Beata Gavurova: https://orcid.org/0000-0002-0606-879X

Jaroslav Belas: https://orcid.org/0000-0002-5900-997X
} 


\section{Introduction}

Many international research studies examine the innovation determinants and their effects on economic growth (Ivanová and Masárová, 2018; Antošová, Arias Gómez and Arias Gómez, 2019; Mohammadali and Abdulkhaliq, 2019). Also, education is considered to be one of the main factors for economic and social growth (Gradstein and Justman, 2002; Krisnaresanti, et al., 2020; Uslu, Alagöz and Güneş, 2020). This can also be said of tourism, which makes a significant contribution to the economic prosperity of countries (Albaladejo, González-Martínez and Martínez-García, 2014; Haller, et al., 2020) and in this context, Li and Chuan (2012) confirmed the bidirectional relationship between economic growth, tourism receipts and education, suggesting a triangular relationship and underlining the importance of research in this area. All these facts underline the importance of research in the dimension of innovations and the dimension tourisms from a macroeconomic point of view.

As can be seen from the literature review, many studies have addressed the issue of innovations and tourism spending at the microeconomic level, but the question remains unanswered at the macroeconomic level. For this reason, the presented study fills this gap in research and focuses on education and research and development (R\&D) as macroeconomic indicators of countries' innovative activity, as well as on selected categories of tourism spending. The study also expands previous knowledge on the relationships between economic development and the development of the tourism sector.

The structure of the study is as follows: the review of the scientific literature is focused on providing the main information on the issue in order to find out where the scientific knowledge is. The methodological section contains a description of the data as well as the methods used in the analytical process. The subsequent section presents the results revealed by statistical methods such as descriptive analysis, panel regression analysis and cluster analysis and, which were formulated into interpretations. The obtained results were the basis for discussion and formulation of implications. The section of the conclusions provides a summary of the most important findings from the study.

\section{Review of the scientific literature}

Tourism spending is a commonly used indicator to express the demand and development of tourism, while Wang and Davidson (2010) highlighted the preference for its use over the use of tourist arrivals, as tourist arrivals do not cover tourists' spending behaviour and their consumption of tourism goods and services. According to the author, the use of tourist arrivals does not capture the economic effect. On the other hand, Fredman (2008) considered tourism spending as a measure of the direct economic effect of tourism on regions or countries. Thus, tourism spending is one of the most relevant indicators to economic approaches and an important part of the national economy of many countries, as it affects several major economic activities such as transportation, accommodation and restaurants (Garcia-Sanchez, Fernandez-Rubio and Collado, 2013). For these reasons, its research significance is unquestionable (Brida and Scuderi, 2013). Given its economic value and the need to increase tourism spending, many researchers have tried to identify their predictors from various perspectives (Fredman, 2008; Wang and Davidson, 2010; Mortazavi and Lundberg, 2020; Park, Woo and Nicolau, 2020; Stefko, et al., 2020). It is 
clear from the knowledge base that this issue is receiving more and more attention at the micro level (Thrane, 2014).

According to Uyen (2019), the main drivers of tourism spending are leisure and business motives. The portfolio of leisure tourism includes many activities that can have an effect on tourism spending, such as sports, attractions, shopping, visiting places of interest, attending a cultural event or consuming in restaurants (David-Negre, Hernandez and Moreno-Gil, 2018). Based on this rich portfolio of activities, it can be stated that leisure tourism has a significant position in terms of total tourism spending. Conversely, business purposes are less represented among tourists, which is reflected in the smaller average number of total trips, overnight stays and spending in individual countries (Ibanescu, Stoleriu and Gheorghiu, 2018). Regarding spending during the trip, there is evidence that business tourists spend more than leisure tourists (Suh and Gartner, 2004; Moll-de-Alba, Prats and Coromina, 2016). It should be noted that all the mentioned categories of tourism and their participants may generate different amounts of spending in various countries.

Education can be translated into many aspects, such as social welfare, human resources, innovations, but also economic life (Rozsa, Formánek and Maňák, 2020). From a deeper point of view, education can also be an important factor for people's spending patterns for a variety of purposes and activities in their life, including tourism activities as a superior and luxury good (Vietze, 2011; Eugenio-Martin and Campos-Soria, 2014). In this sense, many international studies can be found, the results of which have confirmed that the level of education is a significant determinant for tourism spending patterns (Kim, et al., 2011; Hung, Shang and Wang, 2012; Ranasinghe, 2019). In this context, Garcia-Sanchez, Fernandez-Rubio and Collado (2013) found that tourists with a higher level of education have higher spending on tourism and tourists with university education spend on average $12.5 \%$ more than tourists with compulsory education. Similar evidence was revealed by Kim, et al. (2011) or Saayman and Saayman (2011). This fact was also confirmed in specific categories of tourism spending, such as food, accommodation, entertainment, shopping, local transportation and sightseeing (Kim, et al., 2011). On the other hand, not all studies have shown that the level of education is a significant determinant of tourism expenditure (Marrocu, Paci and Zara, 2015). From a macroeconomic point of view, Vietze (2011) examined the literacy rate (as an indicator of educational level of countries) and tourism spending, and a positive correlation was confirmed, but an effect of the literacy rate on international tourism spending was insignificant.

The field of education and the economy are important interconnected attributes in each country, including in a tourism-specialized economy. Simultaneously, innovations can contribute to the development and competitiveness of tourism (Romao and Nijkamp, 2019), and it is therefore necessary to support R\&D. In this sense, $R \& D$ as well as innovations have an irreplaceable place in increasing the carrying capacity of tourism and incomes from the tourism sector (Albaladejo and Martinez-Garcia, 2015); and therefore, attention should be paid to effective improvements in $R \& D$.

Despite the importance of this issue, there is still little evidence of the effects of R\&D and innovation activities on key components of tourism. On the other hand, there is an expectation that the ability of countries to attract tourism visitors depends on its characteristics as a tourist destination (Albaladejo and Martinez-Garcia, 2015), to which innovative activities can also contribute. New and varied tourism goods and services create modern tourist destinations which are more sophisticated and flexible in terms of the 
demand and capacity of tourism (Butler, 2011). In this sense, it is possible to endogenously increase tourist arrivals and the quality of tourism services (Albaladejo, González-Martínez and Martínez-García, 2014) corresponding to the needs of tourists willing to spend money (Alegre and Juaneda, 2006; González, Comesaña and Brea, 2007). However, the whole process is preceded by effective research and development, the output of which is innovations reflected in tourism goods and services in order to attract tourists willing to spend money. In this context, the R\&D-based endogenous growth model of tourism appears to be beneficial, as investment in research and development enables the long-term sustainability of tourism incomes (Albaladejo and Martinez-Garcia, 2015).

Innovations enable development, and education and R\&D are the main components of countries' innovative activity, which can also be reflected in the tourism sector. Also, tourism spending is very important from an economic point of view and countries should strive to increase it. These facts clearly encourage an examination of the relations between education, R\&D and tourism spending not only in developed OECD countries, but also in Romania with great tourism potential. It is the tourism sector that creates new jobs, economic gains and development, and the opportunities revealed by this study would also benefit Romania (Badulescu, et al., 2020). This issue is therefore important in many countries around the world.

\section{Research methodology}

The aim of this study was to evaluate the effect of education and R\&D on tourism spending in the countries of the Organisation for Economic Co-operation and Development (OECD). Based on this aim, the following research questions (RQ) were formulated:

- RQ I: Is there a significant relationship between education and tourism spending in OECD countries?

- RQ II: Is there a significant relationship between tertiary education and tourism spending in OECD countries?

- RQ III: Is there a significant relationship between $\mathrm{R} \& \mathrm{D}$ and tourism spending in OECD countries?

These main components of innovation activities of the countries were examined in order to achieve the primary aim of the study: education and $R \& D$, and also selected groups of tourism spending. The study primarily focuses on the selected OECD countries (36). The Global Innovation Index (GII) reports (2011-2020) that are published by Cornell University, INSEAD and WIPO (2020a) were used to obtain all data about education and R\&D. The Global Innovation Index Report has been published since 2007 (the 1st edition). However, the first versions of the GII did not contain a sufficient number of countries and a methodology had only started to be developed. Thus, the study's analyses are using data since 2011 (the 4th Edition). These data were associated to tourism spending data with an annual delay. Two indicators were examined in terms of education: education (EDU) and tertiary education (TER). The analyses also included the indicator of Research and development (R\&D). The indicators, EDU, TER and R\&D, were measured by an index in a theoretical interval from $0-100$. 
The structure of individual indicators is as follows (Cornell University, INSEAD and WIPO, 2020b):

\section{$E D U$ :}

- Expenditure on education (Government expenditure on education);

- Government funding per secondary student;

- School life expectancy (School life expectancy, primary to tertiary education, both sexes in years);

- Assessment in reading, mathematics, and science;

- Pupil-teacher ratio, secondary.

TER

- Tertiary enrolment (School enrolment, tertiary in \% gross);

- Graduates in science and engineering (Tertiary graduates in science, technology, engineering, and mathematics in \% of total tertiary graduates);

- Tertiary inbound mobility (Tertiary inbound mobility rate in \%).

$R \& D:$

- Researchers FTE (Researchers, full-time equivalent (FTE) per million population);

- Gross expenditure on R\&D;

- Global R\&D companies, average expenditure - top 3 (Average expenditure of the top 3 global companies by R\&D, in US\$);

- QS university ranking score of the top 3 universities (Average score of the top 3 universities at the QS world university ranking).

Data that represent tourism spending were obtained from the World Travel \& Tourism Council database (WTTC, 2020) in the annual interim period from 2010-2019. Also, there were selected four groups of tourism spending for the analyses' purposes: Business Tourism Spending (BTS), Leisure Tourism Spending (LTS), Domestic Tourism Spending (DTS) and Visitor Exports (Foreign Spending) (VEFS). The structure of spending is according to the World Travel \& Tourism Council as follows (WTTC, 2020):

- BTS: spending on business travel within a country by residents and international visitors.

- LTS: spending on leisure travel within a country by residents and international visitors.

- DTS: spending within a country by that country's residents for both business and leisure trips. Multi-use consumer durables are not included since they are not purchased solely for tourism purposes. This is consistent with total domestic tourism expenditure.

- VEFS: spending within the country by international tourists for both business and leisure trips, including spending on transport, but excluding international spending on education. 
As the World Travel \& Tourism Council database shows data in billions (1 000000000 USD per country), the individual indicators were firstly calculated per resident. The population data were obtained from the OECD database (OECD, 2020). Subsequently, the data were calculated (divided) by the purchasing power parity that was obtained from the OECD database (OECD.Stat) (OECD, 2020) - Purchasing Power Parities for GDP per capita (Current PPPs).

The innovation variables in the field of education and R\&D followed the theoretical background and were selected on the basis of a comprehensive concept of GII, in which these variables form one of the essential pillars. The selection of tourism variables was based on a typology of tourism spending that takes into account the boundaries between countries and tourist activities, within which it is possible to distinguish domestic tourists from foreign tourists, and leisure activities from business activities.

The main part of the analyses contains regression models that use data from the OECD countries $(\mathrm{n}=36)$ and the years $(2010-2019)$. The Pooling Model, One-way (individual) effects Within Model, One-way (individual) effect Random Effects Model: Swamy-Arora's transformation (Swamy and Arora, 1972) were applied.

The models' preferences were created on the basis of the outputs from: $F$ test for the presence of individual effects (or time effect), Hausman Test for Panel Models, Angrist Newey's test (Angrist and Newey, 1991), Breusch-Pagan Test, Wooldridge's test for unobserved individual effects (Wooldridge, 2010), Baltagi and Li one-sided LM test (Baltagi and Li, 1995). The Robust Estimation was used to realize the estimations of the regression models on the basis of the outputs of the given tests. The Pooling Model was estimated by means of the Heteroskedasticity-Consistent Covariance Matrix Estimation, and in case of the Within Model, there was used the Arellano method of estimate (Arellano, 1987 ) and the Random model was estimated by the White 2 . These models were marked as the simple panel regression models. The statistical description of the indicators and relations between the indicators was realized by means of the descriptive statistics. The data pre-processing consisted of the outliers' identification by means of the Hampel test (Hawkins, 1980) and subsequently, the outliers were removed and imputed by means of the Multiple imputation by chained equations (Azur, et al., 2011). Also, the cluster analysis was applied by means of the algorithm - the Partitioning Around Medoids (PAM) and the Manhattan Distances, where an optimal number of clusters was estimated by the Silhouette method (Kassambara, 2017; Schubert and Rousseeuw, 2019). The programming language $\mathrm{R}$ v. 4.0.2 was used for analytical processing in R Studio - RStudio, Inc., Boston, MA, U.S.

\section{Results}

This section provides the main results of the study. The outliers were identified by the descriptive statistics, and they were confirmed by the Hampel test. This test helped to remove such outliers as $(\mathrm{N}: \mathrm{EDU}=1 ; \mathrm{TER}=1 ; \mathrm{R} \& \mathrm{D}=0 ; \mathrm{BTS}=7 ; \mathrm{LTS}=14 ; \mathrm{DTS}=0$; VEFS $=26$ ). Then, these values were imputed by the Multivariate imputation by chained equations. The corrected data were used in the analytical processes of the descriptive statistics and in the regression analysis. However, the cluster analysis used data which were not corrected. Table no. 1 shows the indicators that were used in the analyses and divided into two groups: the indicators that present the components of innovation activity (education, R\&D) and the indicators that demonstrate the tourism spending. 
Table no. 1. Descriptive statistics

\begin{tabular}{|l|r|r|r|r|r|r|r|r|r|}
\hline Var & Mean & SD & Median & Trim M & MAD & Min & Max & Skew & Kurt \\
\hline EDU & 58.97 & 8.79 & 58.20 & 58.83 & 8.38 & 37.50 & 86.30 & 0.18 & -0.25 \\
\hline TER & 43.43 & 9.17 & 42.50 & 43.15 & 8.90 & 13.60 & 70.60 & 0.23 & 0.06 \\
\hline R\&D & 49.35 & 20.73 & 49.30 & 49.48 & 26.69 & 9.50 & 94.30 & -0.04 & -1.08 \\
\hline BTS & 498.76 & 264.94 & 492.41 & 477.39 & 296.46 & 112.99 & 1294.95 & 0.54 & -0.40 \\
\hline LTS & 1964.93 & 950.11 & 1816.37 & 1882.26 & 927.54 & 454.76 & 4559.93 & 0.70 & -0.20 \\
\hline DTS & 1430.18 & 849.94 & 1368.64 & 1353.91 & 1000.86 & 197.53 & 3851.90 & 0.62 & -0.38 \\
\hline VEFS & 1013.39 & 646.59 & 813.53 & 949.67 & 532.99 & 66.97 & 2468.10 & 0.78 & -0.56 \\
\hline
\end{tabular}

Notes: Mean - arithmetic mean; SD - standard deviation; Trim M - trimmed mean 5\%; MAD - median absolute deviation; Min - minimum; Max - maximum; Skew - skewness, Kurt - kurtosis

The first group of indicators achieves the value around 50, i.e., the negative fact as the theoretical interval achieves its maximum value 100 (mean: $\mathrm{EDU}=58.97$; $\mathrm{TER}=43.43$; $\mathrm{R} \& \mathrm{D}=49.35)$. The highest variability rate was observed in $\mathrm{R} \& \mathrm{D}(\mathrm{SD}=20.73$; MAD = 26.69). Skewness and kurtosis are in eligible intervals, while the highest value is observed in the kurtosis of $\mathrm{R} \& \mathrm{D}$ indicator (kurt $=-1.08$ ). The highest average value of spending indicators was evident in LTS (mean =1964.93) and the lowest value in BTS (498.76). The characteristics of skewness and kurtosis do not show any significant deviations. The descriptive analysis used only data free of extreme values. Table no. 2 provides an evaluation of the assumptions for the application of regression models.

Table no. 2. Assumptions of panel regression models

\begin{tabular}{|c|c|c|c|c|c|c|c|c|}
\hline Model & $\begin{array}{c}\text { F Test } \\
\text { (effect) } \\
\text { Country }\end{array}$ & $\begin{array}{c}\text { F Test } \\
\text { (effect) } \\
\text { Year }\end{array}$ & $\begin{array}{c}\text { Hausman } \\
\text { (Fixed - } \\
\text { Random) }\end{array}$ & $\begin{array}{c}\text { Reg- } \\
\text { based } \\
\text { Hausman } \\
\text { vcovHC }\end{array}$ & $\begin{array}{c}\text { Angrist } \\
\text { Newey's } \\
\text { test }\end{array}$ & $\begin{array}{c}\text { Wooldridge } \\
\text { Unobserved } \\
\text { Effects }\end{array}$ & $\begin{array}{c}\text { Baltagi- } \\
\text { Li one- } \\
\text { sided } \\
\text { LM }\end{array}$ & $\begin{array}{c}\text { Breusch- } \\
\text { Pagan } \\
\text { Test }\end{array}$ \\
\hline $\mathrm{EDU} \rightarrow \mathrm{BTS}$ & $145.9 \dagger$ & $5.00 \dagger$ & $3.91 * *$ & $31.72 \dagger$ & 39.74 & $4.04 \dagger$ & $11.14 \dagger$ & $20.70 \dagger$ \\
\hline EDU $\rightarrow$ LTS & $110.75 \dagger$ & 1.08 & & 1.9 & 83.37 & $3.73 \dagger$ & $5.77 \dagger$ & 2.06 \\
\hline EDU $\rightarrow$ DTS & $506.89 \dagger$ & 0.75 & $98 * *$ & 1.87 & 50.05 & & $14.36 \dagger$ & 1.15 \\
\hline $\mathrm{EDU} \rightarrow \mathrm{VEFS}$ & $70.51 \dagger$ & $1.99 * *$ & $13.55 \dagger$ & $6.06 * *$ & 54.51 & $3.78 \dagger$ & $4.15 \dagger$ & 0.71 \\
\hline TER $\rightarrow$ BTS & $164.39 \dagger$ & 0.54 & $4.80^{* * *}$ & $2.89 *$ & 43.86 & $3.98 \dagger$ & $11.31 \dagger$ & $7.12 * * *$ \\
\hline TER $\rightarrow$ LTS & $86.53 \dagger$ & 0.99 & $43.48 \dagger$ & $13.55 \dagger$ & 65.33 & $3.51 \dagger$ & $5.68 \dagger$ & $12.70 \dagger$ \\
\hline $\mathrm{TER} \rightarrow \mathrm{DTS}$ & $457.72 \dagger$ & & & $4.76 * * *$ & 47.83 & 3.7 & $14.57 \dagger$ & 1.26 \\
\hline $\mathrm{TER} \rightarrow \mathrm{VEFS}$ & & & & $9.78 * * *$ & 55.8 & 3.7 & $3.99+$ & $21.5 \dagger$ \\
\hline $\mathrm{R} \& \mathrm{D} \rightarrow \mathrm{BTS}$ & $129.49 \dagger$ & 0.55 & $11.24 \dagger$ & $9.98 * * *$ & 67.18 & $3.10 * * *$ & $11.06 \dagger$ & $20.17 \dagger$ \\
\hline $\mathrm{R} \& \mathrm{D} \rightarrow \mathrm{LTS}$ & $113.33 \dagger$ & 0.42 & 0.08 & 0.07 & 88.74 & $3.67 \dagger$ & $5.66 \dagger$ & $6.34 * *$ \\
\hline $\mathrm{R} \& \mathrm{D} \rightarrow \mathrm{DTS}$ & $438.06 \dagger$ & 0.22 & $8.37 * * *$ & $4.33 * *$ & 40.8 & $3.38 \dagger$ & $14.56 \dagger$ & 0.17 \\
\hline $\mathrm{R} \& \mathrm{D} \rightarrow \mathrm{VEFS}$ & $74.7 \dagger$ & 0.52 & 2.54 & 2.49 & 88.55 & $4.02 \dagger$ & $3.91 \dagger$ & $17.86 \dagger$ \\
\hline
\end{tabular}

Notes: $* \mathrm{p}$ value $<0.1 ; * * \mathrm{p}$ value $<0.05 ; * * * \mathrm{p}$ value $<0.01 ; \uparrow \mathrm{p}$ value $<0.001$

The first two columns in Table no. 2 contain the F Test for Individual and/or Time Effects. The first column assesses individual countries and the second column the years' effects. The following models were compared: Pooling model (OLS), the panel Within (fixed) effect model and the panel Random effect model. The test achieves significant metrics in all of the cases within the countries. In a majority of the models, the years' effect is nonsignificant, while significant effect is only evident in EDU $\rightarrow$ BTS $(F=5.00 \dagger)$ and in EDU $\rightarrow$ VEFS $(\mathrm{F}=1.99 * *)$. The third column illustrates the Hausman test output, where it evaluates the effects as significant on the basis of $p$ value $\chi^{2}$ that is lower than 0.05 in most 
of the cases. In these cases, the Within model is more preferable than the Random effect model. However, the Random model is more appropriate in cases of EDU $\rightarrow$ LTS $\left(\chi^{2}=\right.$ 2.27), $\mathrm{R} \& \mathrm{D} \rightarrow \operatorname{LTS}\left(\chi^{2}=0,08\right)$ and $\mathrm{R} \& \mathrm{D} \rightarrow \operatorname{VEFS}\left(\chi^{2}=2.54\right)$. The Robust variant Hausman test (Regression-based Hausman test, vcov: vcovHC) are recommended in those models that show a significant heteroscedasticity. The Within model is supported by the Angrist and Newey's test of Within model presented in the next column as the restrictions are nonsignificant. The Wooldridge's Unobserved Effects and Baltagi-Li one-sided LM test assess the Serial Correlation, while a significant correlation may be observed in all of the cases. Also, it is confirmed by the appropriateness of the Robust approach estimation. The final column shows the stability of residues' variability. In most of the cases, the Breusch-Pagan Test identifies a significant heteroscedasticity. Consequently, it is appropriate to choose the Robust estimation of the coefficients. The regression models in Table no. 3 are presented in three variants: Pooling, Within and Random, where the most suitable approach for an interpretation is a comparison of results with the output of the assumptions' analysis in Table no. 2.

Table no. 3. Regression analysis output

\begin{tabular}{|c|c|c|c|c|}
\hline Model & & Pooling $(\mathrm{SE})^{\mathrm{a}}$ & Within $(\mathrm{SE})^{\mathrm{b}}$ & $\operatorname{Random}(\mathrm{SE})^{\mathrm{c}}$ \\
\hline $\mathrm{EDU} \rightarrow \mathrm{BTS}$ & $\begin{array}{l}\beta \\
\alpha\end{array}$ & $\begin{array}{c}12.18+(6.02,18.34) \\
-219.37(-566.1,127.4)\end{array}$ & $-0.69(-2.52,1.13)$ & $\begin{array}{c}1.03(-3.44,5.51) \\
424.55^{* *}(68.4,780.7)\end{array}$ \\
\hline & $\beta$ & $14.01(-8.90,36.93)$ & & $0.85(-14.38,16.09)$ \\
\hline EDU $\rightarrow$ LTS & $\alpha$ & $1138.54(-228.4,2505.5)$ & $-2.36(-10.31,5.59)$ & $1891.6 * * *(650.1,3133.1)$ \\
\hline & $\beta$ & $12.03(-9.53,33.58)$ & & $-4.74 * * *(-8.30,-1.18)$ \\
\hline $\mathrm{EDU} \rightarrow$ DIS & $\alpha$ & $721(-550.1,1,992.1)$ & $-3.84 \times(-1.42,-0.26)$ & $1,806.16+(1417.5,2194.9)$ \\
\hline $\mathrm{EDU} \rightarrow \mathrm{VEF}$ & $\beta$ & $16.23 * *(3.80,28.66)$ & & $0.97(-10.38,12.33)$ \\
\hline & $\alpha$ & $56.42(-707.1,820)$ & $-0.76(-8.47,6.95)$ & $936.83 * *(21.2,1852.5)$ \\
\hline & $\beta$ & $7.33 *(-0.44,15.09)$ & & $3.31 \dagger(1.39,5.24)$ \\
\hline $\mathrm{TER} \rightarrow \mathrm{BTS}$ & $\alpha$ & $180.56(-148.5,509.6)$ & $0.88(-0.99,2.75)$ & $232.43 * * *(75.1,389.9)$ \\
\hline & $\beta$ & $49.02 \dagger(25.78,72.26)$ & & $0.52(-6.44,7.48)$ \\
\hline TER- & $\alpha$ & $-164.12(-1105.5,777.3)$ & $5.95(-1.15,13.04)$ & $1,916.40 \dagger(1274.6,2558.2)$ \\
\hline TFR $\rightarrow$ DTS & $\beta$ & $24.44 * *(0.92,47.97)$ & $018(-402 \quad 366)$ & $-0.13(-3.54,3.28)$ \\
\hline TER $\rightarrow$ DTS & $\alpha$ & $368.56(-652.5,1389.7)$ & $-0.18(-4.02,3.66)$ & $1,440.61 \dagger(1067.5,1813.7)$ \\
\hline $\mathrm{TER} \rightarrow \mathrm{VEF}$ & $\beta$ & $29.51 \dagger(14.43,44.59)$ & $459(-206 \quad 1124)$ & $-0.49(-5.20,4.21)$ \\
\hline & $\alpha$ & $-268.32(-853.3,316.7)$ & $4.59(-2.00,11.24)$ & $1054.76+(631.1,1478.4)$ \\
\hline & $\beta$ & $6.47 \dagger(2.98,9.95)$ & & $2.54 \uparrow(1.40,3.68)$ \\
\hline $\mathrm{R} \& \mathrm{D} \rightarrow \mathrm{BTS}$ & $\alpha$ & $179.62 * *(18,341.3)$ & $1.1(-0.81,3.01)$ & $300.30+(193.3,407.3)$ \\
\hline & $\beta$ & $2.61(-9.90,15.13)$ & & $9.31 \dagger(4.88,13.73)$ \\
\hline $\mathrm{R} \& \mathrm{D} \rightarrow \mathrm{LTS}$ & $\alpha$ & $1,835.98 \div(1091,2580.9)$ & $4.78(-2.21,11.77)$ & $1204.24+(743.5,1665)$ \\
\hline & $\beta$ & $13.57 * *(2.82,24.33)$ & $=068(-672537)$ & $3.91 * * *(1.51,6.30)$ \\
\hline $\mathrm{R} \& \mathrm{D} \rightarrow \mathrm{I}$ & $\alpha$ & $760.41 * *(179.1,1,341.7)$ & $-0.68(-0 . / 2,5.3 /)$ & $1113.27+(786.6,1440)$ \\
\hline $\mathrm{R} \& \mathrm{D} \rightarrow \mathrm{VEF}$ & $\beta$ & $-3.56(-11.87,4.76)$ & $4.6(-1.48,10.68)$ & $5.30 \dagger(2.26,8.34)$ \\
\hline & $\alpha$ & $1188.91 \dagger(668.6,1709.2)$ & $4.6(-1.48,10.68)$ & $584.00 \div(276.3,891.7)$ \\
\hline
\end{tabular}

Notes: a - Robust Estimation; $\mathrm{b}$ - Arellano estimator; $\mathrm{c}-$ White 2 estimator; $* \mathrm{p}$ value < $0.1 ; * * \mathrm{p}$ value $<0.05 ; * * * \mathrm{p}$ value $<0.01 ; \dagger \mathrm{p}$ value $<0.001$

In general, it is recommended to use the panel models (Within, Random) over the Pooling (OLS) models. The Random model is preferred over the Within model in three cases $(\mathrm{EDU} \rightarrow \mathrm{LTS} ; \mathrm{R} \& \mathrm{D} \rightarrow \mathrm{LTS} ; \mathrm{R} \& \mathrm{D} \rightarrow \mathrm{VEFS})$. It is possible to consider 3 models as significant: $\mathrm{EDU} \rightarrow \mathrm{DTS}(\beta$ Within model $=-3.84 * *)$, R\&D $\rightarrow$ LTS $(\beta$ Random model $=$ $9.31 \dagger)$ and $R \& D \rightarrow \operatorname{VEFS}(\beta$ Random model $=5.30 \dagger)$ on the basis of the conditions 
presented in Table no. 3 and the regression analysis outputs in Table no. 4 at $\alpha$ level, which is lower than 0.05 . Also, it is necessary to consider that the Hausman test is tendentious to the Within model when taking into account the heteroscedasticity model. In such a case, the Random model, significant model, will be taken into account TER $\rightarrow$ BTS ( $\beta$ Random model $=3.31 \dagger)$.

Subsequently, the cluster analysis was realized. This analysis considered the values of selected variables for particular OECD countries. The values of individual countries were created by the arithmetic mean of the values in individual years, and subsequent standardization (from 0 to 1 , where 0 represents the lowest value and 1 the highest value). The PAM algorithm was used in clustering the variables that determine education and R\&D (EDU, TER, R\&D) and considered as the most appropriate one with regard to an existence of outliers. The most suitable number of clusters was 8 on the basis of the outputs of the Silhouette method. Table no. 5, column INNOV, illustrates the countries' affiliation to the individual clusters. Identical approach was chosen in clustering the indicators of international tourism spending (BTS, LTS, DTS, VEFS), while the only difference was the number of clusters that was estimated to 4 in this case. Table no. 5 also includes the column TS which illustrates a particular output.

Similarly, the application of the cluster analysis on the data of the education, R\&D and visitors' spending was realized. The interim step pending, where the arithmetic mean was calculated from those areas, which were re-standardized in the previous steps from 0 to 1 , represents the difference as opposed to previous approaches. Two new variables, INNOV and TS, were created from the indicators of education and R\&D (EDU, TER, R\&D), and also from the indicators of international tourism spending (BTS, LTS, DTS, VEFS). Here, the Silhouette method estimated the number of clusters to 2 . This output is provided in Table no. 4, column CL ALL.

Table no. 4. Average indicators' value in the countries and the clusters (2010-2019)

\begin{tabular}{|l|r|r|r|r|r|r|r|r|r|r|}
\hline ID & INNOV & TS & $\begin{array}{c}\text { CLL } \\
\text { ALDU }\end{array}$ & \multicolumn{1}{|c|}{ TER } & \multicolumn{1}{l}{ R\&D } & \multicolumn{1}{|l}{ BTS } & \multicolumn{1}{c|}{ LTS } & \multicolumn{1}{c|}{ DTS } & \multicolumn{1}{c|}{ VEFS } \\
\hline AUS & 1 & 1 & 1 & 60.74 & 53.3 & 62.84 & 547.34 & 2651.46 & 2550.98 & 647.82 \\
\hline AUT & 1 & 2 & 1 & 60.83 & 60.84 & 57.75 & 579.98 & 3503.43 & 2098.14 & 1985.27 \\
\hline BEL & 2 & 3 & 1 & 68.76 & 40.15 & 56.59 & 429.6 & 1208.42 & 752.54 & 885.48 \\
\hline CAN & 3 & 1 & 2 & 52.19 & 37.42 & 59.9 & 662.11 & 1110.19 & 1382.25 & 390.05 \\
\hline CHE & 1 & 2 & 1 & 57.08 & 49.76 & 72.44 & 517.46 & 2884.63 & 1938.44 & 1463.64 \\
\hline CHL & 4 & 3 & 2 & 46.14 & 34.27 & 17.31 & 268.64 & 1444.86 & 1393.81 & 319.69 \\
\hline CZE & 5 & 3 & 2 & 56.45 & 45.33 & 36.43 & 274.56 & 1178.54 & 600.24 & 852.86 \\
\hline DEU & 1 & 1 & 1 & 59.07 & 47.43 & 68.19 & 616.66 & 2944.88 & 3067.31 & 494.24 \\
\hline DNK & 6 & 1 & 1 & 70.59 & 44.98 & 72.9 & 949.99 & 1504.86 & 1381.31 & 1073.55 \\
\hline EST & 5 & 2 & 1 & 60.37 & 42.22 & 31.48 & 667.23 & 2123.44 & 718.95 & 2071.71 \\
\hline FIN & 6 & 1 & 1 & 69.66 & 54.38 & 73.17 & 787.44 & 2050.94 & 2082.33 & 756.05 \\
\hline FRA & 1 & 1 & 1 & 59.53 & 47.92 & 60.46 & 494.49 & 2049.79 & 1703.98 & 840.3 \\
\hline GBR & 1 & 1 & 1 & 59.59 & 52.31 & 64.62 & 909.18 & 1905.99 & 2319.83 & 495.34 \\
\hline GRC & 7 & 2 & 1 & 62.78 & 57.03 & 27.49 & 231.9 & 3356.29 & 1405.75 & 2182.45 \\
\hline HUN & 8 & 3 & 2 & 55.08 & 34.92 & 33.58 & 136.5 & 1220.84 & 391.91 & 965.42 \\
\hline IRL & 7 & 3 & 1 & 62.05 & 49.39 & 50.55 & 610.72 & 1354.3 & 445.54 & 1519.49 \\
\hline ISL & 2 & 4 & 1 & 65.81 & 41.46 & 51.07 & 1833.72 & 7018.31 & 2941.74 & 5910.28 \\
\hline ISR & 3 & 3 & 1 & 55.99 & 39.45 & 81.67 & 330.36 & 1637.96 & 951.53 & 1016.79 \\
\hline ITA & 5 & 1 & 1 & 55.66 & 37.97 & 39.18 & 610.95 & 2487.39 & 2358.97 & 739.37 \\
\hline
\end{tabular}




\begin{tabular}{|l|c|c|c|r|r|r|r|r|r|r|}
\hline ID & INNOV & TS & $\begin{array}{c}\text { CL } \\
\text { ALL }\end{array}$ & EDU & \multicolumn{1}{c|}{ TER } & \multicolumn{1}{l}{ R\&D } & \multicolumn{1}{c|}{ BTS } & \multicolumn{1}{c|}{ LTS } & \multicolumn{1}{c|}{ DTS } & VEFS \\
\hline JPN & 3 & 1 & 1 & 55.48 & 31.92 & 74.49 & 598.45 & 1228.51 & 1616.64 & 210.31 \\
\hline KOR & 1 & 3 & 1 & 57.62 & 53.91 & 81.27 & 180.41 & 721.94 & 491.1 & 411.25 \\
\hline LTU & 8 & 3 & 2 & 59.9 & 40.27 & 24.34 & 251.93 & 900.14 & 489.91 & 662.17 \\
\hline LUX & 5 & 2 & 1 & 53.28 & 49.99 & 34.99 & 186.15 & 3725.33 & 697.66 & 3213.83 \\
\hline LVA & 8 & 3 & 2 & 58.45 & 35.9 & 14.95 & 273.65 & 1359.09 & 689.5 & 943.24 \\
\hline MEX & 4 & 1 & 2 & 43.9 & 33.38 & 22.24 & 156.94 & 2553.49 & 2390.34 & 320.09 \\
\hline NDL & 2 & 3 & 1 & 62.84 & 35.93 & 58.14 & 435.95 & 1254.94 & 880.26 & 810.64 \\
\hline NOR & 2 & 1 & 1 & 65.01 & 40.86 & 56.1 & 583.46 & 1817.94 & 1689.36 & 712.04 \\
\hline NZL & 7 & 2 & 1 & 66.47 & 52.27 & 46.64 & 1065.99 & 4683.47 & 3556.52 & 2192.94 \\
\hline POL & 8 & 3 & 2 & 57.99 & 33.6 & 25.81 & 179.68 & 484.2 & 213.45 & 450.43 \\
\hline POR & 5 & 2 & 1 & 62.13 & 44.35 & 42.68 & 533.56 & 2890.42 & 1205.31 & 2218.67 \\
\hline SPN & 5 & 2 & 1 & 57.15 & 43.26 & 43.27 & 372.28 & 2798.03 & 1414.81 & 1755.51 \\
\hline SVK & 4 & 3 & 2 & 49.37 & 39.6 & 18.2 & 367.06 & 887.14 & 636.98 & 617.23 \\
\hline SVN & 5 & 2 & 1 & 62.67 & 43.17 & 40.86 & 394.69 & 2235.95 & 907.75 & 1722.89 \\
\hline SWE & 6 & 1 & 1 & 67 & 46.66 & 74.49 & 906.23 & 1888.79 & 1730.99 & 1064.03 \\
\hline TUR & 4 & 3 & 2 & 47.07 & 33.31 & 25.05 & 138.51 & 853.28 & 451.38 & 540.41 \\
\hline USA & 3 & 1 & 1 & 56.71 & 36.4 & 75.4 & 725.06 & 1653.84 & 1939.12 & 439.78 \\
\hline
\end{tabular}

Notes: The higher value, the darker colour of the cells.

Table no. 4 demonstrates an affiliation to clusters, and also average values of indicators of the individual OECD countries. As it was already mentioned, the input values of the indicators into the clusters were standardized from 0 to 1 . The subsequent interpretation is formulated in this interval, i.e., the higher value, the more positive result. The Appendix in this study provides visualisations of all clusters, which also indicate the position of individual countries.

INNOV variable is formed by the following clusters. The first cluster consists of 7 countries: AUS, AUT, CHE, DEU, FRA, GBR, KOR (mean: $\mathrm{EDU}=0.57$; $\mathrm{TER}=0.70$, R\&D $=0.78$ ). The second cluster consists of 4 countries: BEL, ISL, NDL, NOR (mean: $\mathrm{EDU}=0.81$; TER $=0.27, \mathrm{R} \& \mathrm{D}=0.61)$. The third cluster also consists of 4 countries: CAN, ISR, JPN, USA (mean: EDU $=0.42$; TER $=0.15$, R\&D $=0.87$ ). The fourth cluster consists of 4 countries: CHL, MEX, SVK, TUR (mean: EDU $=0.10$; TER $=0.11, \mathrm{R} \& \mathrm{D}=$ 0.09). The fifth cluster consists of 7 countries: CZE, EST, ITA, LUX, POR, SPN, SVN (mean: $\mathrm{EDU}=0.54$; TER $=0.41, \mathrm{R} \& \mathrm{D}=0.35$ ). The sixth cluster consists of 3 countries: DNK, FIN, SWE (mean: EDU $=0.94$; TER $=0.58, \mathrm{R} \& \mathrm{D}=0.88$ ). The seventh cluster also consists of 3 countries: GRC, IRL, NZL (mean: $E D U=0.74$; TER $=0.72, R \& D=0.40$ ). The last cluster consists of 4 countries: HUN, LTU, LVA, POL (mean: EDU $=0.52$; EDU $=0.15, \mathrm{R} \& \mathrm{D}=0.15$ ).

TS variable is formed by the following clusters. The first cluster consists of 13 countries: AUS, CAN, DEU, DNK, FIN, FRA, GBR, ITA, JPN, MEX, NOR, SWE, USA (mean: BTS $=0.31 ; \mathrm{LTS}=0.23, \mathrm{DTS}=0.56, \mathrm{VEFS}=0.07$ ). The second cluster consists of 9 countries: AUT, CHE, EST, GRC, LUX, NZL, POR, SPN, SVN (mean: BTS $=0.22 ;$ LTS $=0.41$, DTS $=0.40$, VEFS $=0.33$ ). The third cluster consists of 13 countries: BEL, CHL, CZE, HUN, IRL, ISR, KOR, LTU, LVA, NDL, POL, SVK, TUR (mean: BTS $=0.01$; LTS = 0.10, DTS $=0.13$, VEFS $=0.10$ ). The last cluster consists of only one country, Island (BTS $=1.00 ;$ LTS $=1.00$, DTS $=0.82$, VEFS $=1.00$ ). 
There were also created two clusters by interconnecting the components' evaluations of innovation activities, i.e., education and $R \& D$ with the group of tourism spending (CL ALL). The first cluster consists of 26 countries (mean: INNOV $=0.60$; TS $=0.31$ ) and the second cluster is composed of 10 countries: CAN, CHL, CZE, HUN, LTU, LVA, MEX, POL, SVK, TUR (mean: INNOV =0.23; TS $=0.11$ ).

\section{Discussion}

Tourism is not a product of an individual's daily consumption, but its considerable share of GDP worldwide reflects the importance of research in this area. In this sense, it is essential to be interested in the various aspects that may affect this sector. One of these aspects is the macroeconomic level of education and R\&D in individual countries, as these are the main components of countries' innovative activities.

Using the descriptive analysis of the data after adjusting for outliers, relatively low mean values were identified in education and R\&D indicators, indicating great potential for improvements in OECD countries. In terms of tourism spending, the highest mean value was found for leisure tourism spending (LTS) and the lowest mean value for business tourism spending (BTS). This finding is not surprising, as leisure tourism consists of a rich portfolio of activities (David-Negre, Hernandez and Moreno-Gil, 2018) and business tourism includes the specific purposes of tourists, which are characterized by a smaller number of total trips, nights and spending compared to leisure purposes (Ibanescu, Stoleriu and Gheorghiu, 2018). These aspects play an important role in explaining our finding, but evidence also shows that business tourists spend more money on their trip than leisure tourists (Suh and Gartner, 2004; Moll-de-Alba, Prats and Coromina, 2016).

Based on the evaluation of assumptions that recommend specific estimation methods for specific regression models, it was possible to confirm a significant effect in three cases $(\mathrm{EDU} \rightarrow \mathrm{DTS}, \mathrm{R} \& \mathrm{D} \rightarrow \mathrm{LTS}$ and $\mathrm{R} \& \mathrm{D} \rightarrow \mathrm{VEFS})$. These results indicated a positive answer to research questions RQ I and RQ III and a negative answer to research question RQ II. In the first case of the effect of education on domestic tourism spending, a negative $\beta$ coefficient was identified, which indicates a very interesting result. Accordingly, improvements in education may lead to reduced domestic tourism spending. This result could be explained by the fact that an improved area of education in a country enables people to achieve a better level of education, which can be reflected in their ability to travel abroad, as some intercultural and language skills are required (Vietze, 2011). In other word, improved education in a country leads to a higher level of education for people who, thanks to their abilities, can consume tourism goods and services in a country other than their home country. However, it should also be noted that Vietze (2011) did not find a significant effect of the literacy rate (as an indicator of countries' educational level) on international tourism spending. In the other analysed cases concerning education, it was not possible to demonstrably confirm significant effects. These findings may correspond to the findings of other studies, in which education did not play a significant role in terms of tourism spending (Marrocu, Paci and Zara, 2015). On the other hand, there are many studies, the results of which have shown that the education level of tourists is a significant determinant of their patterns of spending on tourism (Kim, et al., 2011; Hung, Shang and Wang, 2012), while university and post-graduate education have been emphasized many times in terms of higher spending (Kim, et al., 2011; Saayman and Saayman, 2011; Garcia-Sanchez, 
Fernandez-Rubio and Collado, 2013). On their basis, it was expected that improvements education and tertiary education could lead to their higher total spending on tourism in various categories, but this assumption was not confirmed in this study. It can be stated that the above-mentioned findings of other authors do not correspond to the findings revealed from the perspective addressed in this study, i.e., from the perspective of improvements in education captured in the GII index. The effect of tertiary education on business tourism spending (TER $\rightarrow$ BTS) can be considered with a certain degree of caution as a proven relation indicating a positive trajectory. This may partially confirm the above-mentioned assumption.

With a focus on the effect of $R \& D$ on leisure tourism spending $(R \& D \rightarrow L T S)$ and the effect of $R \& D$ on visitor exports (foreign spending) ( $\& \& D \rightarrow V E F S$ ), positive $\beta$ coefficients were identified. On this basis, it can be concluded that improvements in R\&D may lead to increased leisure tourism spending as well as foreign spending. These findings are in line with the assumption that improving R\&D could lead to higher tourism spending. In this sense, it is possible to rely on several studies whose findings suggest that innovations and $\mathrm{R} \& \mathrm{D}$ can be reflected in tourism as a whole, its demand and capacity, or in new and varied tourism goods and services that may attract tourists willing to spend money (Butler, 2011; Albaladejo and Martinez-Garcia, 2015). It is possible to endogenously increase tourist arrivals and the quality of tourism services (Albaladejo, González-Martínez and MartínezGarcía, 2014) corresponding to the needs of tourists willing to spend money at the destination (Alegre and Juaneda, 2006; González, Comesaña and Brea, 2007). According to the R\&D-based endogenous growth model of tourism, investments in R\&D enable the long-term sustainability of tourism incomes (Albaladejo and Martinez-Garcia, 2015), which are related to tourism spending. The findings of this study can be explained in the sense that improvements in $\mathrm{R} \& \mathrm{D}$ can generate innovations in those areas of tourism that are attractive to both leisure and foreign tourists.

The cluster analysis was performed to identify the situation of the problem in individual countries (see also the Appendix). In terms of the variable that assessed the education and R\&D indicators as well as the tourism spending indicators (CL ALL), the countries such as Island, New Zealand, Austria, Denmark, Finland and Sweden from the first cluster could be considered positive. On the contrary, the second cluster included the countries such as Mexico, Chile, Turkey, the Slovak Republic, Latvia, Poland and Hungary with less positive CL ALL outputs. Based on the effects revealed in the regression analysis, it is possible to propose recommendations to improve the position of countries in terms of indicators. Regarding the obtained mean values (Table no. 4), the countries such as Latvia, Chile, the Slovak Republic, Mexico, Lithuania, Turkey, Poland, Greece, Estonia, and Hungary have a great potential for an improvement in R\&D. Improvements in this area would be beneficial from an innovation perspective, but also from a tourism perspective, as R\&D efforts may also result in a growth in tourism spending ( $R \& D \rightarrow$ LTS and $R \& D \rightarrow V E F S)$. In terms of the leisure spending, it is estimated that the most significant effect will be observed in the countries such as Poland, Turkey, the Slovak Republic and Lithuania (R\&D $\rightarrow$ LTS). The countries such as Chile and Mexico will achieve the most significant effect in foreign tourism spending $(\mathrm{R} \& \mathrm{D} \rightarrow \mathrm{VEFS})$. Also, there are provided lower rates of state budget expenditures on $R \& D$ in these countries. 


\section{Conclusions}

This study fulfilled the two main attributes of research as its added value. This study enriched the fundamental knowledge of the driving forces in countries that affect their prosperity and condition against the macroeconomic background of tourism. There was the lack of research efforts focused on the importance improving the macroeconomic level of education and R\&D in terms of their effects in the tourism sector. The macroeconomic perspective clarifies the final effect of what is happening at the micro level and offers a basis for further research to examine the economic situation in countries. The study results represent a valuable platform for a creation of national and international benchmarking indicators, which are inevitable for multi-dimensional comparative studies.

The aim of the presented study was to evaluate the effects of education and R\&D on tourism spending in a sample of OECD countries. Until now, it could only be assumed that improvements in R\&D could lead to higher tourism spending translating into tourism incomes from a macroeconomic point of view. The main results show several proven effects of education and R\&D on selected categories of tourism spending, which confirms the importance for research in this area with subsequent political and practical implications. In similar research, it is recommended to prefer statistical methods that take into account the structure of countries. Ignoring these effects can lead to distorted conclusions. This is evidenced by the presented calculations, in which several models showed different results when comparing within - fixed (or random) and pooling methods. The pooling method often reveals significant relationships, which is not so common in panel methods.

In terms of political and managerial implications, the findings of this study provide valuable information for the implementation of policies and strategies aimed at increasing tourism spending, which can be translated into tourism revenues. The results, which could be of interest to policy makers and strategic planners in tourism, have shown that the effects of the macroeconomic level of education and R\&D should be kept in mind in the decisionmaking process. It has been shown that effective improvements in education and R\&D in developed countries can have an effect on several categories of tourism spending that should not be ignored and overlooked. In any case, policy makers should seek to increase spending on tourism, which can be transformed into tourism revenues.

Limitations can also be found in this research. One possible limitation was the fact that the innovation data were sub-indices in GII and were collected with some delay by the organization from Cornell University, INSEAD and WIPO. Nevertheless, GII is considered a relevant composite indicator and no significant effect on results is expected. There was also a limitation in the computational aspect, while two models (EDU $\rightarrow$ BTS; EDU $\rightarrow$ VEFS) showed a significant effect in the structure of years. However, in terms of the composition of the overall structure of the calculations, the effect of years was not taken into account, as this effect was not statistically significant in most relations. A potential limitation can also be the process of adjusting the data, in which outliers have been removed and subsequently imputed (maximum 26 values for VEFS). Another limitation may be the fact that the results can only be generalized to countries with a certain level of development (OECD).

As presented, the negative effect of innovations in education on the tourism spending of domestic visitors is very interesting. Future research activities may also focus on this issue and clarify this fact. Another research ambitions will be to analyse relations from the 
perspective of other areas of innovations than those examined in this study. Also, countries such as Romania should be involved in future research.

\section{Abbreviations and acronyms}

AUS - Australia; AUT - Austria; BEL - Belgium; BTS - Business Tourism Spending; CAN - Canada; CHE - Switzerland; CHL - Chile; CZE - Czech Republic; DEU Germany; DNK - Denmark; DTS - Domestic Tourism Spending; EDU - Education; ESP Spain; EST - Estonia; FIN - Finland; FRA - France; GBR - United Kingdom; GDP Gross Domestic Product; GII - Global Innovation Index; GRC - Greece; HUN - Hungary; IRL - Ireland; ISL - Iceland; ISR - Israel; ITA - Italy; JPN - Japan; KOR - Korea; LTS Leisure Tourism Spending; LTU - Lithuania; LUX - Luxembourg; LVA - Latvia; MEX Mexico; NDL - Netherlands; NOR - Norway; NZL - New Zealand; OECD - The Organisation for Economic Co-operation and Development; OLS - Ordinary least square; PAM - Partitioning Around Medoids; POL - Poland; POR - Portugal; R\&D - Research and Development; SVK - Slovak Republic; SVN - Slovenia; SWE - Sweden; TER Tertiary Education; TUR - Turkey; USA - United States; VEFS - Visitor Exports (Foreign Spending).

\section{References}

Albaladejo, I.P., González-Martínez, M.I. and Martínez-García, M.P., 2014. Quality and endogenous tourism: an empirical approach. Tourism Management, 41, pp.141-147. https://doi.org/10.1016/j.tourman.2013.09.006.

Albaladejo, I.P. and Martínez-García, M.P., 2015. An R\&D-based endogenous growth model of international tourism. Tourism Economics, 21(4), pp.701-719. https://doi.org/10.5367/te.2014.0379.

Alegre, J. and Juaneda, C., 2006. Destination loyalty: consumers' economic behavior. Annals of Tourism Research, 33(3), pp.684-706. https://doi.org/10.1016/ j.annals.2006.03.014.

Angrist, J.D. and Newey, W.K., 1991. Over-identification tests in earnings functions with fixed effects. Journal of Business and Economic Statistics, 9(3), pp.317-323. https://doi.org/10.2307/1391296.

Antošová, G., Arias Gómez, J.E. and Arias Gómez, H.Y., 2019. Design tourist planning in Colombian lagged destination: case study Bahía Solano. Journal of Tourism and Services, 10(19), pp.128-152. https://doi.org/10.29036/jots.v10i19.111.

Arellano, M., 1987. Computing robust standard errors for within-groups estimators. Oxford bulletin of Economics and Statistics, 49(4), pp.431-434.

Azur, M.J., Stuart, A.E., Frangakis, C. and Leaf, P.J., 2011. Multiple imputation by chained equations: what is it and how does it work?. International Journal of Methods in Psychiatric Research, 20(1), pp.40-49. https://doi.org/10.1002/mpr.329.

Badulescu, A., Badulescu, D., Simut, R. and Dzitac, S., 2020. Tourism - economic growth nexus. The case of Romania. Technological and Economic Development of Economy, 26(4), pp.867-884. https://doi.org/10.3846/tede.2020.12532. 
Baltagi, B.H. and Li, Q., 1995. Testing AR(1) against MA(1) disturbances in an error component model. Journal of Econometrics, 68(1), pp.133-151. https://doi.org/10.1016/0304-4076(94)01646-H.

Brida, J.G. and Scuderi, R., 2013. Determinants of tourist expenditure: a review of microeconometric models. Tourism Management Perspectives, 6, pp.28-40. https://doi.org/10.1016/j.tmp.2012.10.006.

Butler, R.W., 2011. Tourism Area Life Cycle. Oxford: Goodfellow Publishers Limited.

Cornell University, INSEAD and WIPO, 2020a. About the Global Innovation Index. [online] Available at: <https://www.globalinnovationindex.org/about-gii\#reports> [Accessed 10 December 2020].

Cornell University, INSEAD and WIPO, 2020b. The Global Innovation Index 2020: Who will finance innovation? Ithaca, Fontainebleau, and Geneva.

David-Negre, T., Hernandez, J.M. and Moreno-Gil, S., 2018. Understanding tourists' leisure expenditure at the destination: a social network analysis. Journal of Travel \& Tourism Marketing, 35(7), pp.922-937. https://doi.org/10.1080/10548408.2018.1447533.

Eugenio-Martin, J.L. and Campos-Soria, J.A., 2014. Economic crisis and tourism expenditure cutback decision. Annals of Tourism Research, 44, pp.53-73. https://doi.org/10.1016/j.annals.2013.08.013.

Fredman, P., 2008. Determinants of visitor expenditures in mountain tourism. Tourism Economics, 14(2), pp.297-311. https://doi.org/10.5367/000000008784460418.

Garcia-Sanchez, A., Fernandez-Rubio, E. and Collado, M.D., 2013. Daily expenses of foreign tourists, length of stay and activities: evidence from Spain. Tourism Economics, 19(3), pp.613-630. https://doi.org/10.5367/te.2013.0218.

González, M.E.A., Comesaña, L.R. and Brea, J.A.F., 2007. Assessing tourist behavioral intentions through perceived service quality and customer satisfaction. Journal of Business Research, 60(2), pp.153-160. https://doi.org/10.1016/j.jbusres.2006.10.014.

Gradstein, M. and Justman, M., 2002. Education, social cohesion, and economic growth. American Economic Review, 92(4), pp.1192-1204. https://doi.org/10.1257/ 00028280260344722.

Haller, A.P., Butnaru, G.I., Harsan, G.D.T. and Stefanica, M., 2020. The relationship between tourism and economic growth in the EU-28. Is there a tendency towards convergence? Economic Research-Ekonomska Istrazivanja. https://doi.org/10.1080/ 1331677X.2020.1819852.

Hawkins, D.M., 1980. Identification of outliers. Dordrecht: Springer. https://doi.org/10.1007/978-94-015-3994-4.

Hung, W.T., Shang, J.K. and Wang, F.C., 2012. Another look at the determinants of tourism expenditure. Annals of Tourism Research, 39(1), pp.495-498. https://doi.org/10.1016/j.annals.2011.09.006.

Ibanescu, B.C., Stoleriu, O.M. and Gheorghiu, A., 2018. Gender differences in tourism behaviour in the European Union. Eastern Journal of European Studies, 9(1), pp.23-43.

Ivanová, E. and Masárová, J., 2018. Performance evaluation of the Visegrad Group countries. Economic Research-Ekonomska Istrazivanja, Vol. 31, No. 1, pp.270-289.

Kassambara, A., 2017. Practical guide to cluster analysis in R: Unsupervised machine learning (Volume 1). Paris: STHDA. 
Kim, W. G., Kim, T., Gazzoli, G., Park, Y., Kim, S.H. and Park, S.S., 2011. Factors affecting the travel expenditure of visitors to Macau, China. Tourism Economics, 17(4), pp.857-883. https://doi.org/10.5367/te.2011.0060.

Krisnaresanti, A., Julialevi, K.O., Naufalin, L.R. and Dinanti, A., 2020. Analysis of entrepreneurship education in creating new entrepreneurs. International Journal of Entrepreneurial Knowledge, 8(2), pp.67-76. https://doi.org/10.37335/ijek.v8i2.112.

Li, C.C. and Chuan, O.S., 2012. Tourism receipts, education and economic growth in Malaysia. In: A. Zainal, S.M. Radzi, R. Hashim, C.T. Chik and R. Abu eds., 2012. Current Issues in Hospitality and Tourism Research and Innovations. London: Taylor and Francis, pp.509-514.

Marrocu, E., Paci, R. and Zara, A., 2015. Micro-economic determinants of tourist expenditure: a quantile regression approach. Tourism Management, 50, pp.13-30. https://doi.org/10.1016/j.tourman.2015.01.006.

Mohammadali, Z.M. and Abdulkhaliq, S.S., 2019. Prospects and challenges of entrepreneurship development in the Kurdistan region of Iraq: an overview. International Journal of Entrepreneurial Knowledge, 7(2), pp.4-16. https://doi.org/10.37335/ijek.v7i2.89.

Moll-de-Alba, J., Prats, L. and Coromina, L., 2016. The need to adapt to travel expenditure patterns. A study comparing business and leisure tourists in Barcelona. Eurasian Business Review, 6(2), pp.253-267. https://doi.org/10.1007/s40821-016-0046-4.

Mortazavi, R. and Lundberg, M., 2020. Expenditure-based segmentation of tourists taking into account unobserved heterogeneity: the case of Venice. Tourism Economics, 26(3), pp.475-499. https://doi.org/10.1177/1354816619841713.

OECD, 2020. OECD.Stat. [online] Available at: <https://stats.oecd.org/> [Accessed 10 December 2020].

Park, S., Woo, M. and Nicolau, J.L., 2020. Determinant factors of tourist expenses. Journal of Travel Research, 59(2), pp.267-280. https://doi.org/10.1177/0047287519829257.

Ranasinghe, R., 2019. Antecedents of job performance of tourism graduates: evidence from state university-graduated employees in Sri Lanka. Journal of Tourism and Services, 10(18), pp.16-34. https://doi.org/10.29036/jots.v10i18.83.

Romao, J. and Nijkamp, P., 2019. Impacts of innovation, productivity and specialization on tourism competitiveness - a spatial econometric analysis on European regions. Current Issues in Tourism, 22(10), pp.1150-1169. https://doi.org/10.1080/ 13683500.2017.1366434.

Rozsa, Z., Formánek, I. and Maňák, R., 2019. Determining the factors of the employees' intention to stay or leave in the Slovak's SMEs. International Journal of Entrepreneurial Knowledge, 7(2), pp.63-72. https://doi.org/10.37335/ijek.v7i2.94.

Saayman, M. and Saayman, A., 2011. Determinants of spending: an evaluation of three major sporting events. International Journal of Tourism Research, 14(2), pp.124-138. https://doi.org/10.1002/jtr.841.

Schubert, E. and Rousseeuw, P. J., 2019. Faster k-Medoids clustering: Improving the PAM, CLARA, and CLARANS algorithms. In: G. Amato, C. Gennaro, V. Oria and M. Radovanović eds., 2019. Similarity Search and Applications. SISAP 2019. Lecture 
Notes in Computer Science, 11807. Cham: Springer. https://doi.org/10.1007/978-3-03032047-8_16.

Stefko, R., Dzuka, J., Litavcova, E., Nakatova, D. and Lacny, M., 2020. Psychological characteristics of a tourist as predictors of expenditures: an analytical review and proposal of the predictive model. Contemporary Economics, 14(3), pp.320-336. https://doi.org/10.5709/ce.1897-9254.407.

Suh, Y.K. and Gartner, W.C., 2004. Preferences and trip expenditures-a conjoint analysis of visitors to Seoul, Korea. Tourism Management, 25(1), pp.127-137. https://doi.org/10.1016/s0261-5177(03)00056-6.

Swamy, P.A.V.B. and Arora, S.S., 1972. The exact finite sample properties of the estimators of coefficients in the error components regression models. Econometrica, 40(2), pp.261-275. https://doi.org/10.2307/1909405.

Thrane, C., 2014. Modelling micro-level tourism expenditure: recommendations on the choice of independent variables, functional form and estimation technique. Tourism Economics, 20(1), pp.51-60. https://doi.org/10.5367/te.2013.0254.

Uslu, A., Alagöz, G. and Güneş, E., 2020. Socio-cultural, economic, and environmental effects of tourism from the point of view of the local community. Journal of Tourism and Services, 21(11), pp.1-21. https://doi.org/10.29036/jots.v11i21.147.

Uyen, J.G., 2019. SEM analysis for tourist expenditure in an emerging country. Revista Economia y Sociedad, 24(56), pp.68-81. https://doi.org/10.15359/eys.24-56.4.

Vietze, C., 2011. What's pushing international tourism expenditures? Tourism Economics, 17(2), pp.237-260. https://doi.org/10.5367/te.2011.0039.

Wang, Y. and Davidson, M.C.G., 2010. A review of micro-analyses of tourist expenditure. Current Issues in Tourism, 13(6), pp.507-524. https://doi.org/10.1080/ 13683500903406359.

Wooldridge, J.M., 2010. Econometric analysis of cross-section and panel data. London: The MIT Press.

WTTC, 2020. Tourism spending. [online] Available at: <https://tool.wttc.org/> [Accessed 10 December 2020]. 


\section{Appendix}

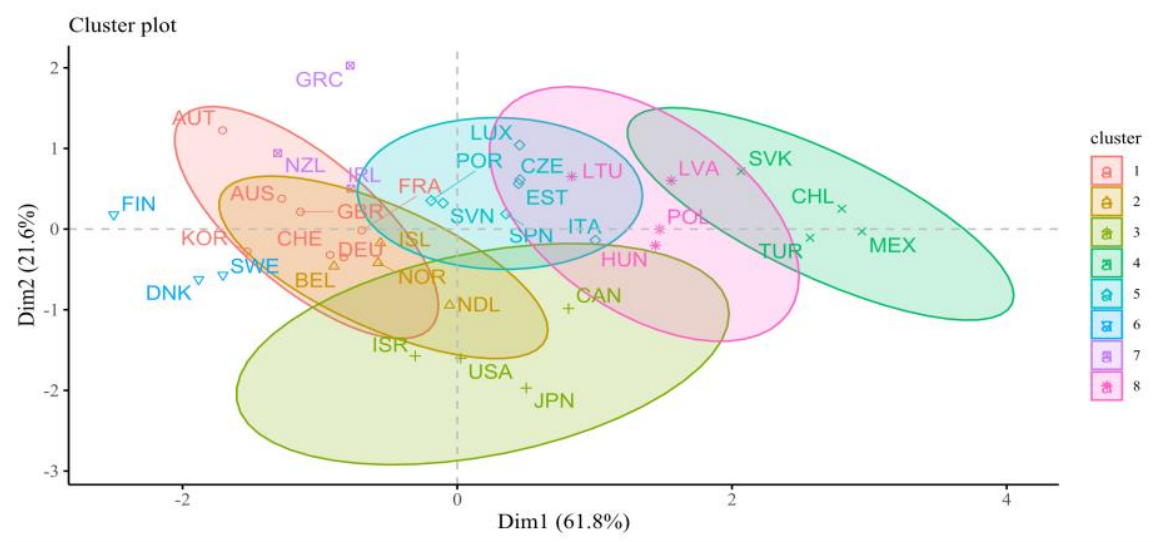

Figure no. 1. Cluster map for education and R\&D indicators (INNOV)

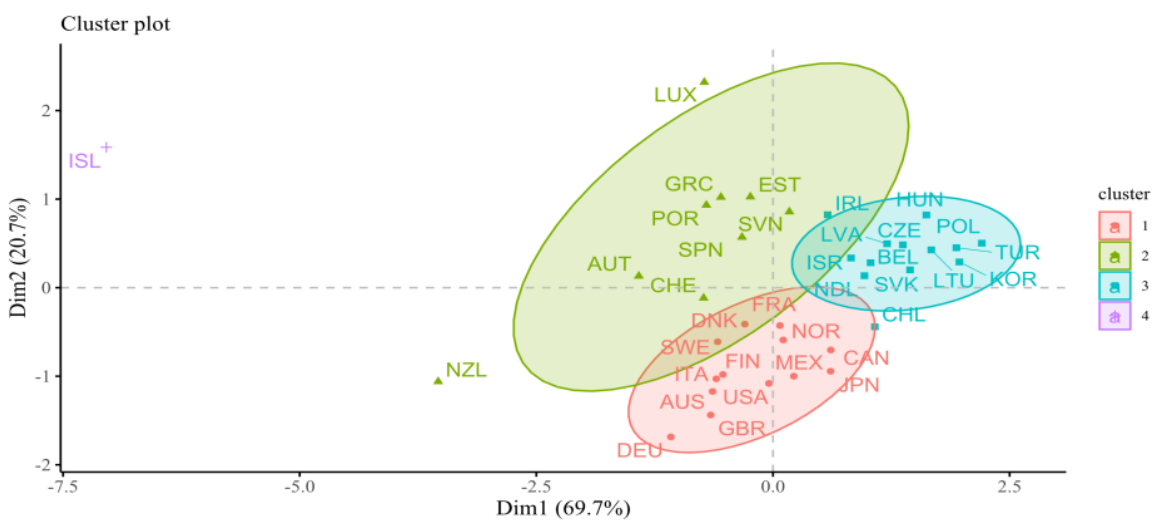

Figure no. 2. Cluster map for tourism spending indicators (TS)

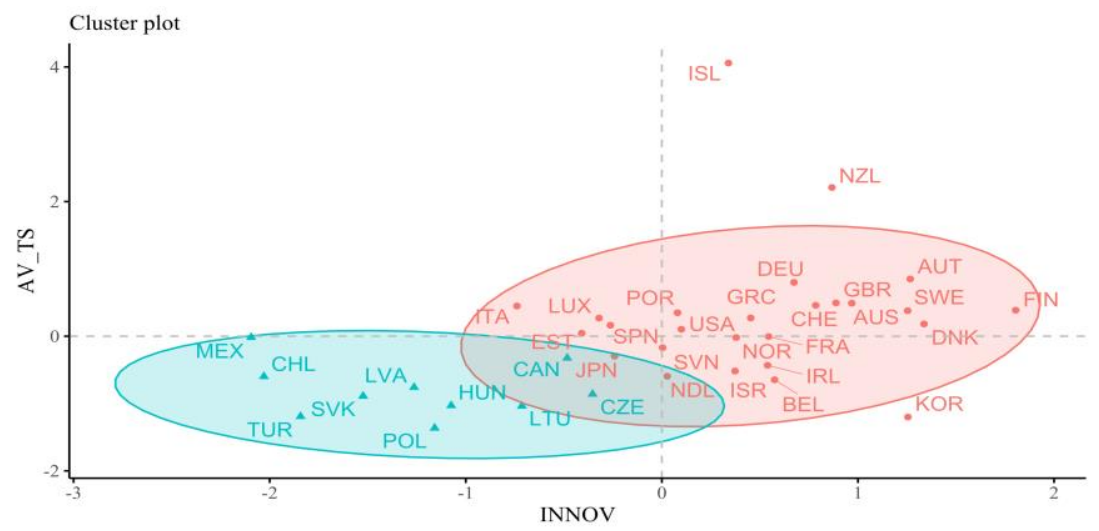

Figure no. 3. Cluster map for the CL ALL variable 